\title{
Amiodarone-induced organizing pneumonia mimicking COVID-19: a case report
}

\author{
Gaetano Zizzo $^{1 *}$ (D, Stefano Caruso ${ }^{2}$, Elisabetta Ricchiuti ${ }^{1}$, Roberto Turato ${ }^{3}$, Ilario Stefani ${ }^{1}$ and \\ Antonino Mazzone ${ }^{1}$
}

\begin{abstract}
Background: Differential diagnosis of interstitial lung diseases (ILDs) during the COVID-19 pandemic is difficult, due to similarities in clinical and radiological presentation between COVID-19 and other ILDs on the one hand, and frequent false-negative swab results on the other. We describe a rare form of interstitial and organizing pneumonia resembling COVID-19, emphasizing some key aspects to focus on to get the right diagnosis and treat the patient properly.

Case presentation: A 76-year-old man presented with short breath and dry cough in the midst of the COVID19 outbreak. He showed bilateral crackles and interstitial-alveolar opacities on X-ray, corresponding on computed tomography (CT) to extensive consolidations with air bronchograms, surrounded by ground glass opacities (GGO). Although his throat-and-nasopharyngeal swab tested negative, the picture was overall compatible with COVID-19. On the other hand, he showed subacute, rather than hyperacute, clinical onset; few and stable parenchymal consolidations, rather than patchy and rapidly evolving GGO; pleural and pericardial thickening, pleural effusion, and lymph node enlargement, usually absent in COVID-19; and peripheral eosinophilia, rather than lymphopenia, suggestive of hypersensitivity. In the past year, he had been taking amiodarone for a history of ventricular ectopic beats. CT scans, in fact, highlighted hyperattenuation areas suggestive of amiodarone pulmonary accumulation and toxicity. Bronchoalveolar lavage fluid (BALF) investigation confirmed the absence of coronavirus genome in the lower respiratory tract; conversely, high numbers of foamy macrophages, eosinophils, and cytotoxic T lymphocytes with low CD4/CD8 T-cell ratio were detected, confirming the hypothesis of amiodarone-induced cryptogenic organizing pneumonia. Timely discontinuation of amiodarone and initiation of steroid therapy led to resolution of respiratory symptoms, systemic inflammation, and radiographic opacities.
\end{abstract}

Conclusions: A comprehensive analysis of medical and pharmacological history, clinical onset, radiologic details, and peripheral and BALF cellularity, is required for a correct differential diagnosis and management of ILDs in the COVID19 era.

Keywords: Amiodarone, Toxicity, COVID-19, Pneumonia, ILD, Diagnosis, Swab, BALF, Lymphocytes, Eosinophils

*Correspondence: gaetano.zizzo@asst-ovestmi.it

${ }^{1}$ Department of Internal Medicine, Legnano and Cuggiono Hospitals, ASST Ovest Milanese, Milan, Italy

Full list of author information is available at the end of the article

\section{Background}

Differential diagnosis of interstitial lung diseases (ILDs) has become challenging during the Coronavirus Disease 2019 (COVID-19) pandemic, especially in those regions most affected by the virus [1]. Nasopharyngeal swab for severe acute respiratory syndrome coronavirus 2 (SARS$\mathrm{CoV}-2)$ detection, using reverse-transcription polymerase chain reaction (RT-PCR), can give false-negative

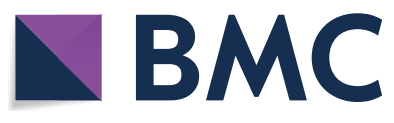

(c) The Author(s) 2021. This article is licensed under a Creative Commons Attribution 4.0 International License, which permits use, sharing, adaptation, distribution and reproduction in any medium or format, as long as you give appropriate credit to the original author(s) and the source, provide a link to the Creative Commons licence, and indicate if changes were made. The images or other third party material in this article are included in the article's Creative Commons licence, unless indicated otherwise in a credit line to the material. If material is not included in the article's Creative Commons licence and your intended use is not permitted by statutory regulation or exceeds the permitted use, you will need to obtain permission directly from the copyright holder. To view a copy of this licence, visit http://creativeco mmons.org/licenses/by/4.0/. The Creative Commons Public Domain Dedication waiver (http://creativecommons.org/publicdomain/ zero/1.0/) applies to the data made available in this article, unless otherwise stated in a credit line to the data. 
results in a non-negligible percentage of cases [2-4], whereas imaging, in particular chest computed tomography (CT), may be suggestive for COVID-19 pneumonia (i.e., highly sensitive), yet not conclusive (poorly specific) $[5,6]$.

We describe a case of ILD that came to our observation in the midst of the COVID-19 outbreak in Lombardy (Northern Italy), which wants to be emblematic in this regard. In this patient, in fact, only the subsequent clinical course and in-depth research of SARS-CoV-2 genome in bronchoalveolar lavage fluid (BALF) allowed us to rule out the hypothesis of COVID-19 pneumonia or other infectious diseases, while an accurate analysis of medical history, clinical onset, radiologic features and BALF cytology finally oriented towards a correct approach to the patient's pathology.

\section{Case presentation}

At the beginning of April 2020, a 76-year-old man presented to the emergency room of Magenta hospital (Milan) with worsening dyspnea and dry cough in the past 2 weeks. He was a former moderate smoker and a retired house painter. He denied fever, chest pain, lower limb edema or palpitations in the last period, although he had suffered from an unspecified arrhythmia a year earlier, for which he had to quit dancing. On auscultation he presented with bilateral, though localized, fine crackles. His chest X-ray showed extensive interstitialalveolar opacities affecting the posterior segment of the right lower lobe and the anterior segment of the left upper lobe, morphologically compatible with COVID19 pneumonia, and right basal pleural effusion (Fig. 1A, B). However, his combined throat-and-nasopharyngeal swab (RT-PCR) tested negative for SARS-CoV-2 infection. Blood tests at presentation demonstrated moderate leukocytosis $(12,600 / \mu \mathrm{L}$; reference range $4000-1000 /$ $\mu \mathrm{L})$, with neutrophilia $(9000 / \mu \mathrm{L}$; reference range 2000 $7000 / \mu \mathrm{L})$ and mild eosinophilia $(700 / \mu \mathrm{L}$; reference range $0-500 / \mu \mathrm{L})$, normal lymphocyte count $(1800 / \mu \mathrm{L}$; reference range $1500-4000 / \mu \mathrm{L}$ ), slight alteration of aspartate aminotransferase $(61 \mathrm{U} / \mathrm{L}$; normal values $\leq 45 \mathrm{U} / \mathrm{L})$, and substantial C-reactive protein (CRP) elevation (11.4 mg/
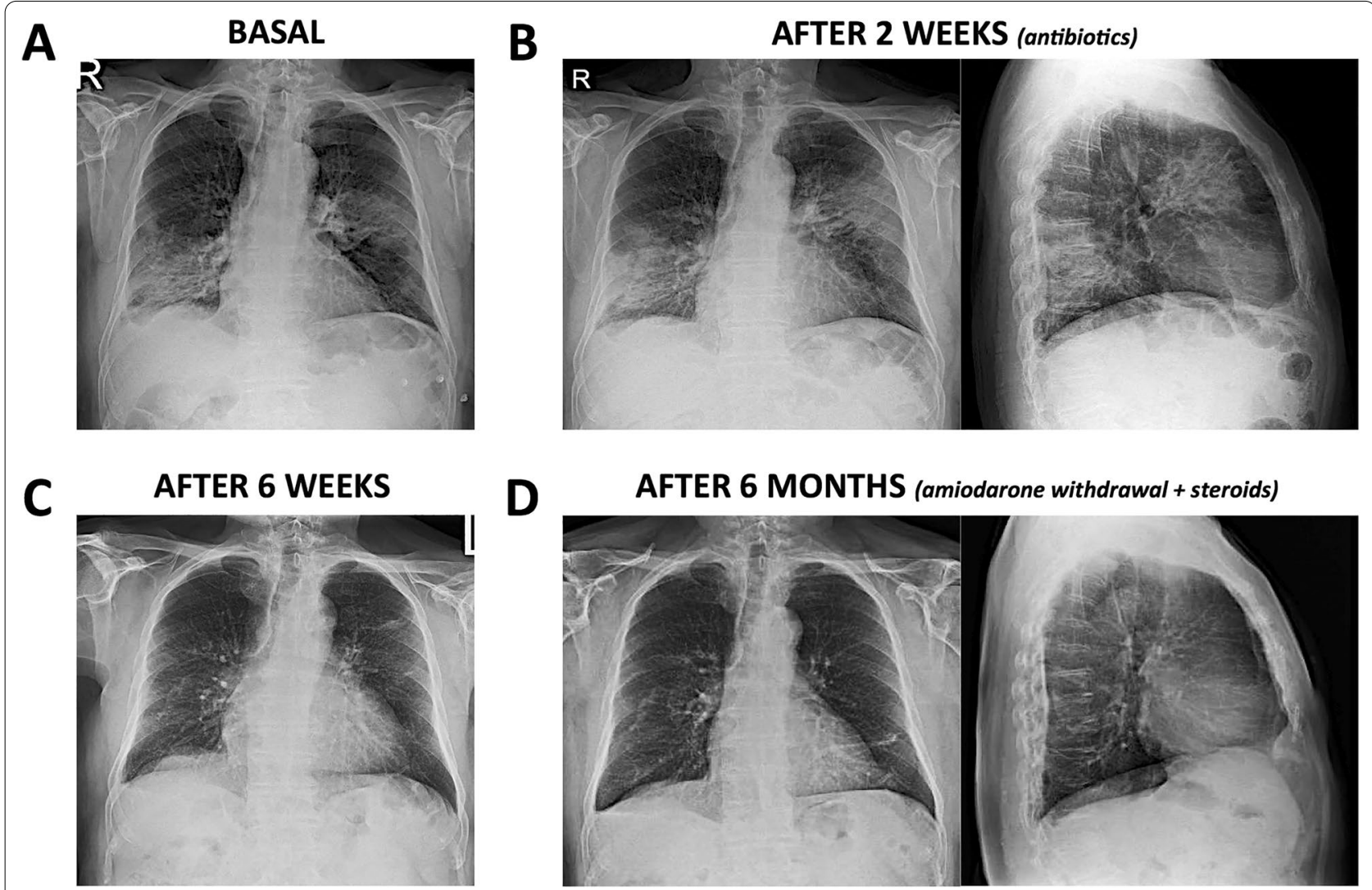

Fig. 1 Chest X-rays. A, B Interstitial-alveolar opacities involving the posterior segment of the right lower lobe and the anterior segment of the left upper lobe; left hilar enlargement; and right basal pleural effusion. Baseline imaging was substantially unchanged after antibiotic therapy. C, D Progressive clearing and resolution of parenchymal opacities, with only right pleural thickening and costophrenic angle obliteration remaining after amiodarone discontinuation and steroid therapy 
$\mathrm{dL}$; normal values $\leq 0.5 \mathrm{mg} / \mathrm{dL}$ ). Gas analysis showed modestly impaired blood oxygen level, with an arterial partial pressure of oxygen $(\mathrm{PaO} 2)$ of $66.4 \mathrm{mmHg}$ (reference range $80-100 \mathrm{mmHg}$ ) and an arterial oxygen saturation $(\mathrm{SaO} 2)$ of $93.5 \%$ (reference range $95-100 \%$ ), no signs of acute respiratory distress syndrome (ARDS) (ratio of $\mathrm{PaO} 2$ to the fraction of inspired oxygen or $\mathrm{P} / \mathrm{F}$ ratio $=316.2 \mathrm{mmHg}$; reference range 400 $500 \mathrm{mmHg}$; values indicative of acute lung injury and ARDS $\leq 300 \mathrm{mmHg}$ ), and values of $\mathrm{pH}$, arterial partial pressure of carbon dioxide and lactates ranging within limits. He was transferred to the nearby Cuggiono hospital in low-flow nasal cannula oxygen therapy for further investigation and treatment.

High-resolution CT (HRCT) scans showed bilateral and subpleural pulmonary consolidations with air bronchograms, surrounded by ground glass opacities (GGO) (Fig. 2A, B). A moderate hilar reactive lymphadenopathy, a partly calcific thickening of the right costal pleura with pleural effusion in the costovertebral groove,
A

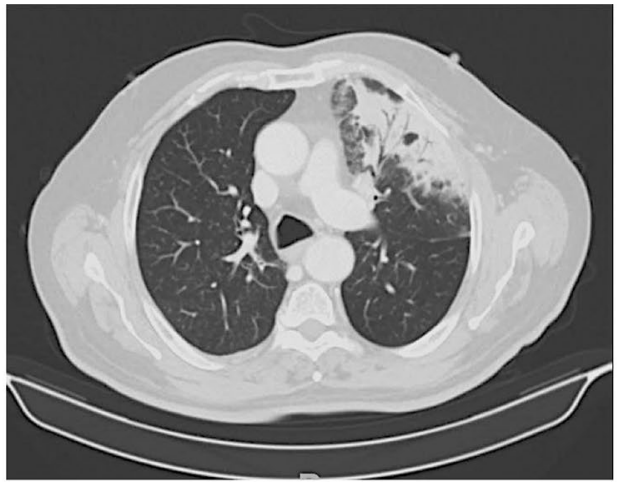

C

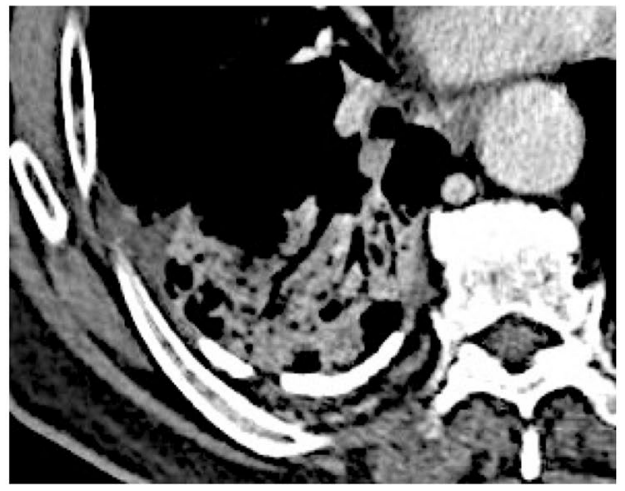

E

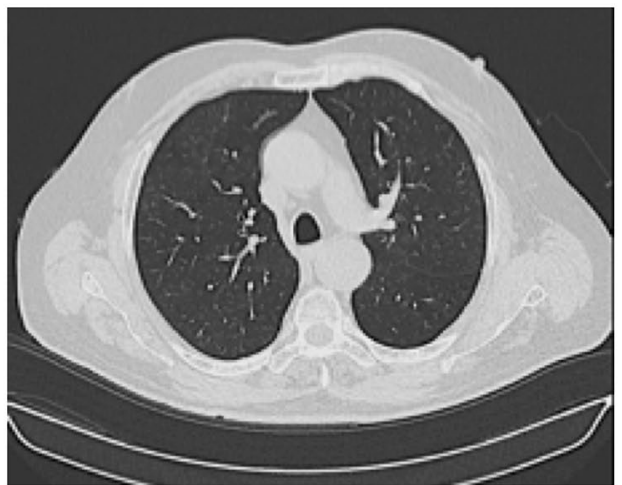

B

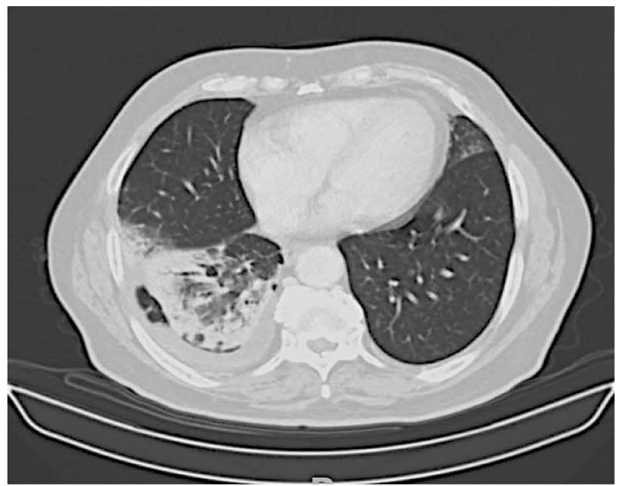

D

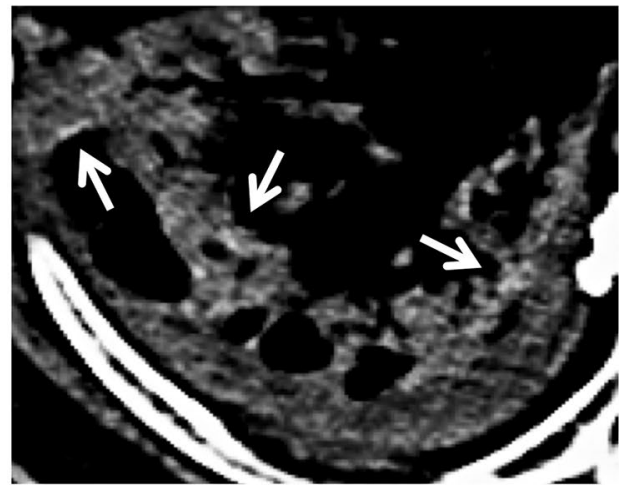

$\mathbf{F}$

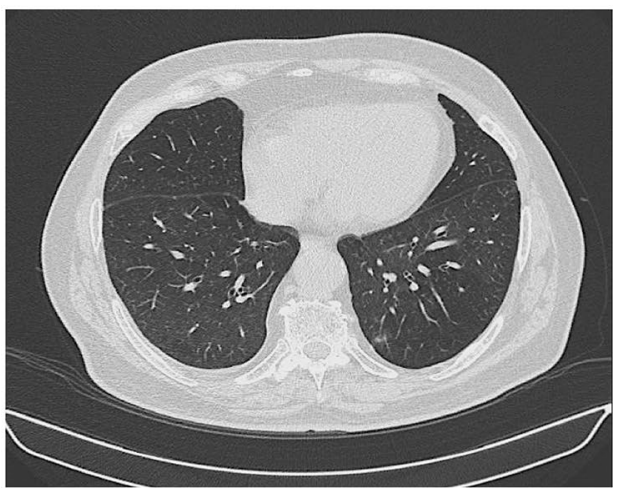

Fig. 2 CT scans. A Left upper lobe consolidation with air bronchograms surrounded by ground glass opacities; left hilar lymphadenopathy. B Right lower lobe consolidation delimited by right oblique fissure with air bronchograms; right basal pleural effusion; left anterior pericardial thickening (lung windows). C Right posterior pleural thickening and calcification. D Areas of hyperattenuation (110-125 Hounsfield units) (arrows) possibly caused by iodine accumulation (mediastinal windows). E, F Complete resolution of parenchymal consolidations and pleural effusion following treatment with glucocorticoids and amiodarone wash-out 
and a modest left anterior pericardial thickening were also observed (Fig. 2A-C).

Empirically, he was initially treated with a broadspectrum antibiotic therapy (meropenem $1 \mathrm{~g} / 8 \mathrm{~h}$ and azithromycin $500 \mathrm{mg} / 24 \mathrm{~h}$ ) for 2 weeks, with poor clinical benefit on crackles and unchanged control chest radiography (Fig. 1B), although pulmonary gas exchange slightly improved ( $\mathrm{PaO} 269.9 \mathrm{mmHg}, \mathrm{SaO} 294.7 \%)$ and he was weaned off oxygen. Control blood tests showed partially reduced, still persistently high, CRP levels (8.5$8.6 \mathrm{mg} / \mathrm{dL}$ ), with further increasing eosinophil counts (up to $1200 / \mu \mathrm{L}$, and $11.8 \%$ of total leukocytes). Serum galattomannan (Aspergillus) antigen and anti-neutrophil cytoplasmic antibodies (ANCA) tested negative, and he underwent bronchoalveolar lavage for further investigation. Cultures from BALF did not grow any bacteria, fungi or mycobacteria, and no cancer cells were found in BALF specimens. Notably, RT-PCR analysis on BALF samples and serological chemiluminescent immunoassay were confirmed negative for SARS-CoV-2 infection and SARS-CoV-2 antibodies. BALF showed markedly increased cellularity $(1,159,000$ cells $/ \mathrm{mL}$; reference range $80,000-200,000 / \mathrm{mL}$ ) and was highly enriched in lymphocytes $(24.7 \%$; normal values $\leq 10 \%)$, with large predominance of $\mathrm{CD}^{+} \mathrm{T}$ cells $(\mathrm{CD} 4 / \mathrm{CD} 8$ ratio $=0.2$; reference range $1.2-1.8)$, and milder increase in neutrophils (3.2\%; normal values $<3 \%$ ) and eosinophils $(3.9 \%$; normal values $\mathrm{a}<2 \%$ ); moreover, approximately one third of total macrophages $(65.7 \%$; normal values $\geq 80 \%$ ) displayed a foamy aspect (21.3\%).

Given the presence of eosinophilia and the massive alveolar infiltration by cytotoxic T lymphocytes (CTL), we finally tested the hypothesis that such form of organizing pneumonia was due to some chronic drug exposure and toxicity. For years, the patient was taking dutasteride and tamsulosin for prostatic hyperplasia, and cyclic rifaximin therapy for diverticular disease. Remarkably, in the last year, he was also taking amiodarone for an arrhythmia that he could not better specify. His electrocardiogram reported normal sinus rhythm with QT interval falling within limits, blood concentration of N-terminal prohormone of brain natriuretic peptide was normal, and his echocardiogram did not show significant abnormalities. His family was then asked to bring previous cardiological documentation. We, therefore, ascertained that the patient had suffered from ventricular ectopic beats after exertion, with numerous extrasystoles being reported at Holter monitoring. Echocardiography had ruled out the presence of structural heart disease, and a stress test had shown no inducible ischemia. Assuming it was a cryptogenic organizing pneumonia (COP) secondary to amiodarone, after having consulted a cardiologist, amiodarone was withdrawn and replaced with low doses of bisoprolol. Moderate doses of prednisone $(37.5 \mathrm{mg}$ per day, corresponding to $\cong 0.5 \mathrm{mg} / \mathrm{kg} /$ day) were then started, to be tapered over at least 6 months. Abstention from excess physical activity and regular control of blood pressure and heart rate were adviced, with cardiological re-evaluation after few weeks. Bisoprolol was soon stopped for bradycardia, and a new Holter was planned after a congruous amiodarone washout period; thyroidstimulating hormone, lactate dehydrogenase, creatine kinase and transaminases were normal.

An X-ray repeated 6 weeks later already showed complete resolution of the parenchymal opacity in the right lower field, with no pleural effusions, and a residual small area of parenchymal thickening in the left upper field (Fig. 1C). After 6 months, all lung fields were clear, with only pleural thickening remaining on the right lung (Fig. 1D).

The patient reported symptom resolution with no side effects, subjective well-being, and normal pulse oxymetry (peripheral oxygen saturation $=98 \%$ ). Blood tests showed normal leukocyte and eosinophil counts (9200-9300/ $\mu \mathrm{L}$ and $200 / \mu \mathrm{L}$, respectively), with normal CRP levels $(0.1-0.3 \mathrm{mg} / \mathrm{dL})$ and low erythrocyte sedimentation rates $(4-5 \mathrm{~mm} / \mathrm{h}$; normal values $\leq 15 \mathrm{~mm} / \mathrm{h})$. A control HRCT scan performed at 8 months (while taking $6.25 \mathrm{mg}$ of prednisone per day, $<0.1 \mathrm{mg} / \mathrm{kg} /$ day) confirmed stable remission of lung consolidations (Fig. 2E, F), thus allowing steroid discontinuation.

\section{Discussion and conclusions}

Accuracy in the diagnosis of COVID-19 and in the differential diagnosis of ILDs during the COVID-19 outbreak is still an unmet need. RT-PCR assays have shown high rates of false-negative results when searching SARS-CoV-2 genome in the upper respiratory tract [2$4,7]$. Sensitivity of nasopharyngeal swabs has increased over the time of the pandemic, from $45-65 \%$ in the first months [2,3] to approximately $75-85 \%$ later $[8,9]$. Despite improved methodology, sensitivity of RT-PCR tests still remains substantially affected by timing. Nasopharyngeal swabs show the best sensitivity in the first week after symptom onset (80-85\%), yet they show low sensitivity during disease incubation (up to $100 \%$ of falsenegative results), and in the second and third week after symptom onset (from one third to two thirds of falsenegative results, respectively) $[4,10]$.

Given its high sensitivity, CT is used as an important complement to the nasopharyngeal swab for diagnosing COVID-19; however, it also shows low specificity [5, 6]. Therefore, it is critically important to examine additional diagnostic clues. Here, we highlight the key contribution of different items, namely medical history, clinical presentation, radiologic details, and BALF data, 
to make a correct differential diagnosis of ILDs during the pandemic.

The patient we describe may have easily been misdiagnosed as having COVID-19 pneumonia with a falsenegative swab. In fact, he presented in the midst of the COVID-19 outbreak with worsening dyspnea and dry cough, had variable increase in peripheral leukocytes, $\mathrm{C}$-reactive protein and transaminases, and showed interstitial lung thickening with bilateral and subpleural GGO and consolidations.

On the other hand, he also presented with distinctive clinical, radiological and laboratory features pointing to alternative diagnostic hypotheses, especially in light of his recent exposure to amiodarone (Table 1). Clinically, the subacute presentation, in the absence of acute respiratory failure $(\mathrm{P} / \mathrm{F}$ ratio $>300 \mathrm{mmHg})$, fever, fatigue or myalgia, contrasted with the acute or hyperacute onset characteristic of viral respiratory diseases such as COVID-19, and was consistent with the progressive tissue accumulation of amiodarone in the last year and correlation of amiodarone-induced pulmonary toxicity (APT) with its cumulative dose [11-14]. In fact, whereas ARDS is frequently observed in COVID-19, amiodaroneinduced ARDS has been described only occasionally, and

Table 1 Comparison between Amiodarone-induced and COVID-19 pneumonia

\begin{tabular}{|c|c|c|}
\hline & Amiodarone-induced organizing Pneumonia & COVID-19 Pneumonia \\
\hline Clinical onset & Subacute or chronic (drug accumulation over 6-12 months) & Acute or hyperacute (rapid evolution) \\
\hline Short breath & Common & Common \\
\hline Dry cough & Common & Common \\
\hline Fever & Absent or mild & Moderate or high \\
\hline Fatigue and Myalgia & Absent or mild & Severe and debilitating \\
\hline Other symptoms & Bradycardia, thyroid dysfunction, blue-grey skin, etc & Anosmia, conjunctivitis, diarrhea, etc \\
\hline $\begin{array}{l}\text { Lactate dehydrogenase and transami- } \\
\text { nase elevation }\end{array}$ & Absent or mild & Moderate or severe \\
\hline Hypoxia & Absent or mild (P/F ratio > 300 mmHg) & Moderate or severe (P/F ratio $\leq 200-300 \mathrm{mmHg}$ ) \\
\hline ARDS & Rare (after cardiothoracic surgery) & Frequent \\
\hline Bilateral pneumonia & Common (right and upper lobes) & Common (lower lobes) \\
\hline Interstitial and alveolar opacities & Common & Common \\
\hline Consolidations with air bronchograms & Predominant & Frequent \\
\hline Ground glass opacities & Frequent & Predominant \\
\hline Multifocal distribution & Fewer segments and lobes involved & $\begin{array}{l}\text { Many segments }(\cong 6) \text { and lobes }(\cong 3) \text { involved } \\
\text { (patchy distribution) }\end{array}$ \\
\hline Hyperattenuation on CT & Frequent (iodine accumulation) & Absent \\
\hline Pleural thickening (and effusion) & Frequent & Absent or rare \\
\hline Pericardial thickening & Frequent & Absent or rare \\
\hline Lymphoadenopathy & Frequent (moderate and reactive) & Absent or rare (lymph node atrophy) \\
\hline Response to steroids & Good & Variable \\
\hline Pulmonary thrombosis & Rare & Frequent \\
\hline Peripheral leukocytosis & Frequent & Frequent \\
\hline Peripheral neutrophilia & Frequent & Common \\
\hline Peripheral eosinophilia & Common & Absent or rare \\
\hline Peripheral lymphopenia & Absent & Common \\
\hline Alveolar hypercellularity & Common & Common \\
\hline Alveolar neutrophilia & Frequent & Common \\
\hline Alveolar eosinophilia & Common & Absent or rare \\
\hline Alveolar lymphocytosis & Common & Absent or variable \\
\hline Alveolar $\mathrm{CD} 8^{+} \mathrm{T}$ cells & Increased & Decreased or variable \\
\hline Alveolar foamy macrophages & Common & Absent or variable \\
\hline RT-PCR on BALF samples & Negative & Positive for SARS-CoV-2 RNA \\
\hline
\end{tabular}

P/F ratio: arterial partial pressure of oxygen divided by the fraction of inspired oxygen; ARDS: acute respiratory distress syndrome; CT: computed tomography; RT-PCR: reverse transcriptase polymerase chain reaction; BALF: bronchoalveolar lavage fluid; SARS-CoV-2 RNA: severe acute respiratory syndrome coronavirus 2 ribonucleic acid 
specifically in patients undergoing cardiothoracic surgery [12]. Furthermore, in our patient, amiodarone may have caused a latent cardiac toxicity, unmasked by his tendency to bradycardia while taking low doses of bisoprolol [12].

Radiologically, the patient basically showed two large pulmonary consolidations with air bronchograms, already present at clinical onset and stable over at least 2 weeks, thereby compatible with amiodarone-induced COP [15]. By contrast, COVID-19 pneumonia is generally characterized by multifocal patchy distribution involving many lobes and segments, rapidly confluent GGO, and more extensive GGO than consolidations $[16,17]$. Remarkably, pleural and pericardial thickening, in some cases with pleural effusion as in our patient, are frequently observed after amiodarone exposure [12-15], but not in COVID-19 [16-18]. Similarly, lymph node enlargement, even moderate as seen in our patient, is not typical of COVID-19 [16-18], in which a diffuse lymphopenia is indeed associated with the atrophy of secondary lymphoid organs [19]. Additional radiological details pointing to the diagnosis of APT and COP, rather than COVID-19, were the preponderant involvement of the right lung and pleura, the presence of hyperattenuation areas (Fig. 2D), and the complete clearing of radiographic opacities upon treatment with moderate doses of steroids, as previously described $[12,14,15,20]$.

Blood tests were also suggestive in this regard, highlighting the presence of eosinophilia, rather than lymphopenia, a milder neutrophilia and a lower neutrophil-to-lymphocyte ratio as compared to COVID-19, and only a transient and non-specific rise in aspartate aminotransferase level $[12,15,16,19]$.

Our report strongly supports the use of bronchoscopy with bronchoalveolar lavage as a valuable tool for discriminating COVID-19 pneumonia from other ILDs. BALF analysis is desirable for an in-depth search of SARS-CoV-2 genome when the clinical and radiological picture is suggestive of COVID-19 pneumonia but the nasopharyngeal swab is negative, due to the higher sensitivity of RT-PCR testing in BALF specimens (up to $93-100 \%)[4,7]$. BALF investigation also allows to rule out other infections or malignancies. Most remarkably, BALF provides precious information about alveolar cellularity. In our patient, the presence of eosinophilia, in peripheral blood (i.e, eosinophils $>1000 / \mu \mathrm{L}$ ) as at the alveolar level (ie, eosinophils $>2-3 \%$ of total leukocytes), was strongly suggestive of drug-induced pneumonia or hypersensitivity pneumonitis. As generally observed for APT [15], alveolar eosinophil count did not reach the diagnostic criteria for eosinophilic pneumonia (i.e., eosinophils $>25 \%$ ), and other causes of pulmonary eosinophilia, such as asthma, fungal or mycobacterial infections, and ANCA-positive eosinophilic granulomatosis with polyangiitis were excluded. Furthermore, the conspicuous presence of foamy macrophages in the patient's BALF importantly reflected the typical "amiodarone effect" observed on phospholipid metabolism, the lack of which made the hypothesis of APT very unlikely $[12,13,15]$. Conversely, the high contents of $\mathrm{CD} 8 \mathrm{~T}$ cells in the patient's alveoli was highly suggestive in this regard $[13,15]$. In fact, a low CD4/CD8 T cell ratio in BALF or an overt lymphoid alveolitis (i.e., lymphocyte count $>15 \%$ ) with preponderance of CTL, either isolated or associated with eosinophilic or neutrophilic alveolitis, have been described as key cytological characteristics of amiodarone-induced pneumonia [21], and are consistent with our experience. By contrast, in progressing COVID19 pneumonia, alveolar CD8 T cells, although phenotypically activated in a proinflammatory manner, decrease in numbers, in parallel with general lymphopenia [22, 23].

Obviously, amiodarone-induced COP is a diagnosis of exclusion [13, 15]; on the other hand, a number of elements strongly suggest this hypothesis, including subacute presentation and temporal relationship to amiodarone administration, radiologic aspects, cytological findings, and response to therapies. While the partial reduction of CRP levels and the modest improvement in respiratory exchanges after antibiotic therapy, in the absence of microbiological findings, might have been ascribed to discrete anti-inflammatory effects of azithromycin (e.g., on mitogen-activated protein kinases [24]), only the timely withdrawal of the pneumotoxic agent (amiodarone) and addition of steroids in adequate starting doses (prednisone $0.5 \mathrm{mg} / \mathrm{kg} /$ day) [12, 14, 15] finally led to prompt and complete resolution of pulmonary consolidations, with normalization of oxygen exchange, and drastic reduction of eosinophilia and inflammatory indices. Furthermore, the fact that the slow tapering of steroids was able to protect from disease relapse is consistent with the long elimination half-life of amiodarone, which may actually persist in the body for up to 6-8 months [13].

In conclusion, the COVID-19 pandemic is severely challenging clinicians' ability to differentially diagnose interstitial and organizing pneumonia. Our case report emphasizes the importance of carefully considering (a) medical history (including past and pharmacological history), (b) clinical presentation (e.g., subacute $v s$. acute or hyperacute onset), (c) radiological findings (e.g., predominance of parenchymal consolidations vs. patchy GGO, presence $v s$. absence of pleural or pericardial or lymph node thickening, specific details such as amiodaroneassociated hyperattenuation), and (d) BALF study (for indepth research of coronavirus, exclusion of other causes, and analysis of cellularity and CD4/CD8 $\mathrm{T}$ cell ratio at 


\section{the alveolar level), to correctly guide the physician in the management of ILDs in the "COVID-19 era".}

\begin{abstract}
Abbreviations
ANCA: Anti-neutrophil cytoplasmic antibodies; APT: Amiodarone-induced pulmonary toxicity; ARDS: Acute respiratory distress syndrome; BALF: Bronchoalveolar lavage fluid; CD: Cluster of differentiation; COP: Cryptogenic organizing pneumonia; COVID-19: Coronavirus Disease 2019; CRP: C-reactive protein; CT: Computed tomography; CTL: Cytotoxic T lymphocytes; GGO: Ground glass opacity; HRCT: High-resolution computed tomography; ILD: Interstitial lung disease; PaO2: Arterial partial pressure of oxygen; P/F ratio: Arterial partial pressure of oxygen divided by the fraction of inspired oxygen; RT-PCR: Reverse transcriptase polymerase chain reaction; SaO2: Arterial oxygen saturation; SARS-CoV-2: Severe acute respiratory syndrome coronavirus 2.
\end{abstract}

\section{Acknowledgements}

Not applicable.

\section{Authors' contributions}

GZ managed the patient during hospitalization, searched the literature, wrote the manuscript, and designed the figures and table; SC managed the patient during hospitalization; ER performed bronchoscopy and gave specialist pulmonology consultancy and follow-up; RT gave specialist cardiology consultancy and follow-up; IS managed the patient during hospitalization and edited the manuscript; AM critically edited the manuscript. All authors read and approved the final manuscript.

\section{Funding}

No funding was received for this work.

\section{Availability of data and materials}

Clinical, laboratory and instrumental data pertaining to the patient are available from the corresponding author on reasonable request.

\section{Declarations}

Ethics approval and consent to participate Not applicable.

\section{Consent for publication}

The patient herein described gave written informed consent for publication. A copy of the signed consent is available for review by the Editors of this journal.

\section{Competing interests}

The authors declare that they have no competing interests.

\section{Author details}

'Department of Internal Medicine, Legnano and Cuggiono Hospitals, ASST Ovest Milanese, Milan, Italy. ${ }^{2}$ Unit of Endoscopy, Cuggiono Hospital, ASST Ovest Milanese, Milan, Italy. ${ }^{3}$ Division of Cardiorespiratory Medicine, Cuggiono Hospital, ASST Ovest Milanese, Milan, Italy.

\section{Received: 8 March 2021 Accepted: 22 May 2021}

Published online: 27 June 2021

\section{References}

1. Mazzone A, Mumoli N. Reorganizing Italian internal medicine wards for COVID 19. Eur J Intern Med. 2020;77:143. https://doi.org/10.1016/j.jim. 2020.04.059.

2. Liu M, Li Q, Zhou J, Ai W, Zheng X, Zeng J, et al. Value of swab types and collection time on SARS-COV-2 detection using RT-PCR assay. J Virol Methods. 2020;286:113974. https://doi.org/10.1016/j.jviromet. 2020.113974

3. Bwire GM, Majigo MV, Njiro BJ, Mawazo A. Detection profile of SARS-CoV-2 using RT-PCR in different types of clinical specimens: a systematic review and meta-analysis. J Med Virol. 2021;93:719-25. https://doi.org/10.1002/jmv.26349.

4. Yang Y, Yang M, Yuan J, Wang F, Wang Z, Li J, et al. Laboratory diagnosis and monitoring the viral shedding of SARS-CoV-2 infection. Innovation. 2020;1:100061. https://doi.org/10.1016/j.xinn.2020.100061.

5. Kovács A, Palásti P, Veréb D, Bozsik B, Palkó A, Kincses ZT. The sensitivity and specificity of chest CT in the diagnosis of COVID-19. Eur Radiol. 2020. https://doi.org/10.1007/s00330-020-07347-x.

6. Xu B, Xing Y, Peng J, Zheng Z, Tang W, Sun Y, et al. Chest CT for detecting COVID-19: a systematic review and meta-analysis of diagnostic accuracy. Eur Radiol. 2020;30:5720-7. https://doi.org/10.1007/ s00330-020-06934-2.

7. Wang W, Xu Y, Gao R, Lu R, Han K, Wu G, et al. Detection of SARSCoV-2 in different types of clinical specimens. JAMA. 2020;323:1843-4. https://doi.org/10.1001/jama.2020.3786.

8. Clerici B, Muscatello A, Bai F, Pavanello D, Orlandi M, Marchetti GC, et al. Sensitivity of SARS-CoV-2 detection with nasopharyngeal swabs. Front Public Health. 2021:8:593491. https://doi.org/10.3389/fpubh.2020. 593491.

9. Butler-Laporte G, Lawandi A, Schiller I, Yao M, Dendukuri N, McDonald EG, et al. Comparison of saliva and nasopharyngeal swab nucleic acid amplification testing for detection of SARS-CoV-2: a systematic review and meta-analysis. JAMA Intern Med. 2021;181:353-60. https://doi.org/ 10.1001/jamainternmed.2020.8876.

10. Kucirka LM, Lauer SA, Laeyendecker $\mathrm{O}$, Boon D, Lessler J. Variation in false-negative rate of reverse transcriptase polymerase chain reactionbased SARS-CoV-2 tests by time since exposure. Ann Intern Med. 2020;173:262-7. https://doi.org/10.7326/M20-1495

11. Ernawati DK, Stafford L, Hughes JD. Amiodarone-induced pulmonary toxicity. Br J Clin Pharmacol. 2008;66:82-7. https://doi.org/10.1111/j. 1365-2125.2008.03177.x

12. Wolkove N, Baltzan M. Amiodarone pulmonary toxicity. Can Respir J. 2009:16:43-8. https://doi.org/10.1155/2009/282540.

13. Schwaiblmair M, Berghaus T, Haeckel T, Wagner T, von Scheidt W. Amiodarone-induced pulmonary toxicity: an under-recognized and severe adverse effect? Clin Res Cardiol. 2010;99:693-700. https://doi. org/10.1007/s00392-010-0181-3.

14. Colby R, Geyer H. Amiodarone-induced pulmonary toxicity. JAAPA. 2017;30:23-6. https://doi.org/10.1097/01.JAA.0000524713.17719.c8.

15. Papiris SA, Triantafillidou C, Kolilekas L, Markoulaki D, Manali ED. Amiodarone: review of pulmonary effects and toxicity. Drug Saf. 2010:33:539-58. https://doi.org/10.2165/11532320-000000000-00000

16. Yang W, Cao Q, Qin L, Wang X, Cheng Z, Pan A, et al. Clinical characteristics and imaging manifestations of the 2019 novel coronavirus disease (COVID-19): a multi-center study in Wenzhou city, Zhejiang. China J Infect. 2020;80:388-93. https://doi.org/10.1016/j.jinf.2020.02. 016.

17. Ng M, Lee E, Yang J, Yang F, Li X, Wang $H$, et al. Imaging profile of the COVID-19 infection: radiologic findings and literature review. Radiol Cardiothorac Imaging. 2020;2:e200034. https://doi.org/10.1148/ryct. 2020200034

18. Guan CS, Lv ZB, Yan S, Du YN, Chen H, Wei LG, et al. Imaging features of coronavirus disease 2019 (COVID-19): evaluation on thin-section CT. Acad Radiol. 2020;27:609-13. https://doi.org/10.1016/j.acra.2020.03. 002.

19. Zizzo G, Cohen PL. Imperfect storm: is interleukin-33 the Achilles heel of COVID-19? Lancet Rheumatol. 2020;2:e779-90. https://doi.org/10. 1016/S2665-9913(20)30340-4.

20. Coulier B, Colin GC, Beniuga G. Amiodarone-induced cryptogenic organizing pneumonia (COP). Diagn Interv Imaging. 2020;101:623-5. https://doi.org/10.1016/j.diii.2020.01.004

21. Akoun GM, Cadranel JL, Blanchette G, Milleron BJ, Mayaud CM. Bronchoalveolar lavage cell data in amiodarone-associated pneumonitis. Evaluation in 22 patients. Chest. 1991;99:1177-82. https://doi.org/10. 1378/chest.99.5.1177.

22. Liao M, Liu Y, Yuan J, Wen Y, Xu G, Zhao J, et al. Single-cell landscape of bronchoalveolar immune cells in patients with COVID-19. Nat Med. 2020;26:842-4. https://doi.org/10.1038/s41591-020-0901-9.

23. Zhou Y, Fu B, Zheng X, Wang D, Zhao C, Qi Y, et al. Pathogenic T-cells and inflammatory monocytes incite inflammatory storms in severe 
COVID-19 patients. Natl Sci Rev. 2020;7:998-1002. https://doi.org/10. 1093/nsr/nwaa041.

24. Parnham MJ, Erakovic Haber V, Giamarellos-Bourboulis EJ, Perletti G, Verleden GM, Vos R. Azithromycin: mechanisms of action and their relevance for clinical applications. Pharmacol Ther. 2014;143:225-45. https://doi.org/10.1016/j.pharmthera.2014.03.003.

\section{Publisher's Note}

Springer Nature remains neutral with regard to jurisdictional claims in published maps and institutional affiliations.
Ready to submit your research? Choose BMC and benefit from:

- fast, convenient online submission

- thorough peer review by experienced researchers in your field

- rapid publication on acceptance

- support for research data, including large and complex data types

- gold Open Access which fosters wider collaboration and increased citations

- maximum visibility for your research: over $100 \mathrm{M}$ website views per year

At BMC, research is always in progress.

Learn more biomedcentral.com/submissions 